\title{
Attributes of Good E-learning Mentors According to Learners
}

\author{
Atsuko Tominaga ${ }^{1, *}$, Chiharu Kogo ${ }^{2}$ \\ ${ }^{1}$ Center for Meta-Learning, Future University Hakodate, Japan \\ ${ }^{2}$ Faculty of Human Sciences, Waseda University, Japan
}

Copyright $\odot 2018$ by authors, all rights reserved. Authors agree that this article remains permanently open access under the terms of the Creative Commons Attribution License 4.0 International License

\begin{abstract}
Due to the expansion of the Internet, more people are learning through on-demand e-learning. E-mentor plays an important role in supporting learners in e-learning courses. In this research, we created an original questionnaire about the necessary attributes for e-mentors by: 1) describing the required attitudes and behaviors of e-mentors as well as the necessary knowledge and skills; 2) categorizing the responses; 3) creating 31 question items on e-mentor attributes from these categories; and 4) having 260 e-learners respond to the 31 -item questionnaire. We conducted exploratory and confirmatory factor analyses to identify five factors that enhanced e-mentors' attributes. Factor 1, "Guidance to learners" comprised five items such as "E-mentor can help in precisely pointing out a learner's mistake." Factor 2, "Support for learners" comprised three items such as "E-mentor can give frequent feedback to questions posed by learners." Factor 3, "Consideration for learners" comprised two items such as "E-mentor can use words that do not confuse or demotivate learners." Factor 4, "Cooperation with teachers" comprised two items such as "E-mentors can work with teachers while consulting." Factor 5, "Motivating learners" comprised two items such as "E-mentor can offer support to motivate learners." Comparison of these factors with the face-to-face mentoring functions indicated that "Guidance to learners" and "Motivating learners" were common, however, "Support for learners" and "Consideration for learners" were unique to e-mentoring, while "Cooperation with teachers" was a factor unique to e-mentoring in Japan.
\end{abstract}

Keywords E-mentor, E-mentoring, Attributes, E-learning

\section{Introduction}

The widespread use of the Internet has enabled universities and companies to effortlessly provide e-learning classes. An e-mentor is indispensable in e-learning classes to ensure e-learners attain their goals without dropping out mid-course. Therefore, good e-mentors are very important for successful e-learning classes. In this research, we conducted a questionnaire survey among e-learners and identified the factor structure for good e-mentor attributes.

\subsection{E-mentoring Function}

Ensher and Murphy [1] defined e-mentoring as a mutually beneficial relationship between an e-mentor and an e-learner that provides new learning as well as career and emotional support, primarily through e-mails and other electronic tools (e.g., instant messaging, chat rooms, social networking spaces, etc.). E-mentoring can intersect geographic boundaries and time zones, demonstrating that electronic medium can be particularly useful in various forms of mentoring such as peer mentoring, group mentoring, and reverse mentoring.

However, these advantages can also be potential drawbacks. Ensher et al. [2] mention that some of the disadvantages of e-mentoring are: (a) likelihood of miscommunication, (b) slower development of relationship online than in face-to-face mentoring, (c) requiring competency in written communication and technical skills, (d) computer malfunctions, and (e) issues of privacy and confidentiality.

Early e-mentoring and e-mentor studies reported e-mentoring practices as well as the job responsibilities and roles of an e-mentor [3-6, etc.]. Matsuda and Harada [6] cite instructional designers, content specialists, instructors, and mentors as e-learning professionals. Among them, instructors and mentors were listed as having direct communication with e-learners and possessing organized roles (See Table 1). Essentially, instructors provided educational content, playing a "teaching" role, namely they were teachers. Meanwhile, mentors played a "supporting" role, supplementing learners' learning activities.

Recently, there has been increasing research to analyze 
the influence of e-mentoring on learners [7-12, etc.]. For example, on a sample of graduate and undergraduate students, de Janasz and Godshalk [9] examined the relationship with dyad characteristics, mentoring function (career development, psychosocial support, and role modeling) and students' learning. Career development comprised five question items such as "My e-mentor provides advice on career progress." Psychosocial support also comprised five items such as "My e-mentor offers support and encouragement," while role modeling comprised three items such as "I try to model my behavior after my e-mentor". Based on the question items, the mentoring function was also paraphrased as attributes (attitude, behavior, ability, and skill) an e-mentor required. They revealed that interaction frequency was positively associated with career development and psychosocial support. Furthermore, significant positive correlations were found between career development and skill self-efficacy, and between career development and learning through e-mentoring. A significant positive correlation was also observed between psychosocial support and skill self-efficacy. E-learner satisfaction was positively correlated with psychosocial support and role modeling. Therefore, it follows that mentoring is one of the factors influencing e-learners' learning.

de Janasz and Godshalk's [9] mentoring function was based on Scandura's [13] traditional face-to-face mentoring function that comprised three factors: vocational mentoring (e.g., My mentor has given advice on promotions), role modeling (e.g., I have admired my mentor's ability to motivate others), and social support (e.g., I exchange confidences with my mentor). Kram [14] and Burke [15] also provided factors in face-to-face mentoring functions. Kram's research identified two factors - vocational (career coaching) and psychosocial (social support). Burke found three factors: career development, psychosocial, and role modeling. Scandura, Kram, and Burke's factor structures are almost identical, and de Janasz and Godshalk's mentoring function has appropriated these traditional face-to-face mentoring functions.

As stated previously, since e-mentoring has some drawbacks peculiar to online interactions, certain attributes specific to online mentoring functions that are essential for an e-mentor must exist. Morris and Zuluaga [12] conducted a survey on students who took online courses. Results revealed that the most important determinant of online learning outcomes is frequent e-learner/staff interaction. In addition, an interview survey was conducted on e-mentors who supported them. Interview data indicated that it was important for e-mentors to swiftly comprehend the actual problem and provide timely feedback in order to communicate online effectively. They also listed the characteristics of successful online e-learner/staff interactions: 1) staff comprehends the correct problem in each student email, 2) staff explains the problem/solution in casual, practical terms, and 3) staff exudes a friendly demeanor, but only following the student's lead. It is expected that such online specific attributes (attitude, behavior, ability, and skill) will be included in the e-mentoring function.

Hypothesis 1: Since e-mentoring has specific online drawbacks, it is possible that unique e-mentor attributes (attitude, behavior, ability, and skill) different from face-to-face mentors, may be required.

Table 1. Difference between teacher and mentor [12]

\begin{tabular}{c|c|c}
\hline & Teacher & Mentor \\
\hline Primary role & Instruction & Learning support \\
\hline Specific job & $\begin{array}{c}\text { Teach, Instruct, } \\
\text { Evaluate grades }\end{array}$ & $\begin{array}{c}\text { Encourage, Support } \\
\text { progress management, } \\
\text { Propose an effective } \\
\text { learning method }\end{array}$ \\
\hline $\begin{array}{c}\text { Characteristics } \\
\text { necessary for job }\end{array}$ & $\begin{array}{c}\text { Authoritative, Good } \\
\text { presentation }\end{array}$ & $\begin{array}{c}\text { Friendly, Good } \\
\text { response and advice }\end{array}$ \\
\hline
\end{tabular}

\subsection{Japanese E-mentor}

In 2001, Japanese universities were allowed to acquire credits through asynchronous e-learning. Yoshida [16] reviewed the extent of e-learning in Japan, the United States, Australia, Canada, Europe, Singapore, China, and Korea. Despite Japan's existing infrastructure, she notes that few universities can actually offer exclusive e-learning classes delivered over the Internet at remote locations and acquire all the units necessary for graduation. This is because there are no social practices for Japanese adults, who are the main e-learners, to receive retraining at university.

In e-learning, in addition to faculty members, learning supporters such as e-mentors are required. Even in Japan, research studies indicate the necessity for e-mentors. Seki et al. [17] conducted an interview survey on adult learners who graduated from an online university, analyzing their admission motivation and factors for continuing schooling. "School continuation factors" were divided into three categories - environment, human relations, and self-and "teacher/mentor," a subcategory of human relations, was identified. If the relationship with teachers and mentors is good, it will be a continuing factor, but if there is a problem, it will be an impediment factor. Ishikawa et al. [18] conducted a survey to clarify how students in an online university use self-regulated learning and problem-solving strategies. Results revealed that students' problem-solving strategies involved "asking my schoolmates," "asking my coaches," "omitting problems," and "solving by myself." At these online universities, there are e-mentors who have received specialized training. However, in Japan, few universities have arranged such specialists adequately, a factor that impedes 
the spread of e-learning [19]. Despite establishing a support system by mentors, in some cases, $60 \%$ of the students did not understand the support system sufficiently and completed the course without using it even once [20]. Compared to the United States where the mentoring system is widely recognized, the mentoring system in Japan is relatively unknown.

Hypothesis 2: E-learners in Japan may require e-mentors to possess attributes (attitude, behavior, ability, and skill) that reflect Japanese e-learning circumstances.

\section{Methods}

This study conducted a preliminary and main survey with the aim of creating an original questionnaire regarding necessary e-mentor attributes.

\subsection{Preliminary Survey}

To prepare the question items, a preliminary online survey was conducted for students $(n=62)$ of $X$ University taking on-demand, e-learning classes supported by e-mentors. The online course at X University was established in 2003. All X University's online course e-mentors possess master's degrees and experience. Before beginning work, they receive face-to-face training ( 1 day) and on-line training ( 2 weeks). In addition, they receive face-to-face training once a year. We asked the following three questions based on the students' experiences, to consider a mentor's attitude, behavior, and ability:

1) What kind of attitude do you want in your mentor? Alternatively, mention an attitude that the mentor should not have.

2) What kind of behavior do you want from your mentor? Alternatively, mention a behavior that the mentor should not demonstrate.

3) What are the knowledge and skills required in a mentor?

The answer format was free description. Altogether there were 29 respondents ( 9 men, 20 women; mean age 41.10 years, $\mathrm{SD}=6.72$; response rate $46.8 \%$ ). The first author and one graduate student analyzed the response data using the KJ method. The KJ method is an idea-generating methodology to gather qualitative data [21]. It was developed by Jiro Kawakita, a Japanese ethnologist, and has been widely recognized as a useful, creative, brainstorming technique in Japanese business and administrative circles [22]. Results revealed nine distinct categories of attitudes and behaviors that learners expected from their e-mentors (Dos), 10 categories of attitudes and behaviors they wanted e-mentors to avoid (Don'ts), and six categories of knowledge and skills that they felt were necessary for e-mentors (See Table 2).
Table 2. KJ method results

\begin{tabular}{|c|c|}
\hline & Category \\
\hline Dos & $\begin{array}{c}\text { Cooperation with teachers, } \\
\text { Quick feedback, } \\
\text { Meticulous support, } \\
\text { Empathetic attitudes/behaviors, } \\
\text { Affinity, } \\
\text { Humility, } \\
\text { Fairness, } \\
\text { Calm, } \\
\text { Common-sense attitudes/behaviors }\end{array}$ \\
\hline Don'ts & $\begin{array}{l}\text { Attitudes/behaviors like teachers, } \\
\text { Inappropriate attitudes/behaviors as e-mentors, } \\
\text { Overbearing, } \\
\text { Stern, } \\
\text { Forsaking, } \\
\text { Unfair, } \\
\text { No response, } \\
\text { Default, } \\
\text { False, } \\
\text { Businesslike }\end{array}$ \\
\hline $\begin{array}{c}\text { Knowledge and } \\
\text { skills }\end{array}$ & $\begin{array}{c}\text { Specialized subject skills, } \\
\text { IT skills, } \\
\text { Writing skills, } \\
\text { Reading skills, } \\
\text { Communication skills, } \\
\text { Teaching skills }\end{array}$ \\
\hline
\end{tabular}

Dos: Attitudes and behaviors that learners expected of e-mentors

Don'ts: Attitudes and behaviors that learners want e-mentors to avoid

\subsection{Main Survey}

For the main survey, 31 question items on e-mentor attributes were created from the categories listed in Table 2. The participants $(n=260)$ were $X$ University correspondence course students. They responded to the question "How important are the question items on e-mentor attributes?" in five stages.

\section{Results and Discussion}

\subsection{Factor Selection (Exploratory Factor Analysis)}

Exploratory factor analysis (least squares method, promax rotation) was conducted using valid data $(n=169$; 58 men, 111 women; mean age 45.05 years, $S D=9.88$; response rate $65.0 \%$ ). Five factors were identified from a scree plot, and factor analysis was conducted eliminating items with a loading of less than .40 or with a multiple loading of over .40. Eventually, 22 interpretable items were obtained and the cumulative contribution ratio through the five factors was $71.48 \%$ (See Table 3 ).

Items whose factor loading was .40 or less were " 16 . E-mentor can be a supporting member as a substitute for teachers" and "21. E-mentor can actively praise the learner's good points." Item 16 is similar to "06. E-mentor can teach learners on behalf of teachers." Item 06 was specifically described as "teach learners," while Item 16 was described as "supporting member," not clarifying the 
kind of support. Therefore, it is presumed that factor loading of any factor was low. Item 21 was described as "praise," but it was not included in the psychosocial support within Janasz and Godshalk's [9] mentoring function. Since e-learners do not need "praise" from e-mentors, it is presumed that factor loading was low.

There were seven multiple loading items: " 14 . E-mentor can calmly respond to any comments from learners," "15. E-mentor can grasp learners' questions and comments accurately," "25. E-mentor can teach how to learn," "26. E-mentor can grasp the degree of understanding of learners," "28. E-mentor can have familiar language," "30. E-mentor can show empathy to learners' questions and opinions," and " 31 . E-mentor can fairly correspond with all learners." These items were considered to be related to multiple factors.

\subsection{Examination of Goodness of Fit of Factor Structure (Confirmatory Factor Analysis)}

To examine the goodness of fit of the factor structure of the 22 items derived from the five factors extracted using exploratory factor analysis, a confirmatory factor analysis was conducted. IBM SPSS Amos Version 23.0 (IBM) was used for the analysis. Using covariance structure analysis to examine the goodness of fit of the model resulted in goodness of fit indices of GFI $=0.825, \mathrm{AGFI}=0.777, \mathrm{CFI}$ $=0.916$, and RMSEA $=0.077$, which was rather low. On analyzing again after deleting items with low normalization coefficient, the goodness of fit indices were GFI $=0.915, \quad$ AGFI $=0.867, \quad \mathrm{CFI}=0.970$, and RMSEA $=0.061$, obtaining a better fit than the first model (see Figure 1). Cronbach's alpha coefficient was 0.893 for Factor 1, 0.858 for Factor 2, 0.790 for Factor 3, 0.866 for Factor 4, and 0.745 for Factor 5, and these are relatively sufficient levels. Significant positive correlations were found among all factors (see Table 4). Based on these results, the model in Fig. 1 was adopted as the factor structure for e-mentor attributes in this study.

Factor 1, "Guidance to learners" comprised five items such as "E-mentor can help in precisely pointing out a learner's mistake" and "E-mentor can intelligibly help learners in problem solving." Factor 2, "Support for learners" comprised three items such as "E-mentor can offer support that matches the level of the learner" and "E-mentor can give frequent feedback to questions posed by learners." Factor 3, "Consideration for learners" comprised two items such as "E-mentor can use words that do not confuse or demotivate learners." Factor 4, "Cooperation with teachers" comprised two items such as "E-mentors can work with teachers while consulting." Factor 5, "Motivating learners" comprised two items such as "E-mentor can offer support to motivate learners." The means and standard deviations of the items of each factor are provided in Table 5.

Table 3. Exploratory factor analysis results

\begin{tabular}{|c|c|c|c|c|c|}
\hline & Factor 1 & Factor 2 & Factor 3 & Factor 4 & Factor 5 \\
\hline 06. E-mentor can teach learners on behalf of teachers & .915 & -.179 & -.006 & -.063 & .055 \\
\hline 23. E-mentor can intelligibly help learners in problem solving & .821 & .193 & -.065 & -.070 & -.163 \\
\hline 09. E-mentor can teach specialized knowledge intelligibly & .803 & -.005 & .039 & -.052 & .043 \\
\hline 05. E-mentors can offer advice to learners from a professional viewpoint & .784 & -.050 & .066 & -.052 & .026 \\
\hline 24. E-mentor can help in precisely pointing out a learner's mistake & .730 & .191 & -.153 & .124 & -.142 \\
\hline 07. E-mentor can offer advice to learners to promote their learning & .632 & -.163 & .149 & .069 & .249 \\
\hline 20. E-mentor can offer advice to help e-learners in their learning & .577 & .117 & -.055 & .168 & .054 \\
\hline 27. E-mentor can provide immediate feedback to questions posed by learners & .064 & .871 & .000 & -.124 & -.032 \\
\hline 17. E-mentor can give frequent feedback to questions posed by learners & .046 & .854 & .024 & -.044 & .074 \\
\hline 12. E-mentor is always available to give feedback to questions posed by learners & -.090 & .819 & -.020 & .022 & .097 \\
\hline 13. E-mentor can intelligibly teach e-learners how to operate a PC & -.107 & .584 & .014 & .047 & .166 \\
\hline 29. E-mentor can wait till the learner resolves a doubt & .280 & .548 & .122 & -.050 & -.103 \\
\hline 18. E-mentor can offer support that matches the level of the learner & .277 & .474 & .046 & .126 & .011 \\
\hline 03. E-mentor should refrain from looking down on learners & -.032 & -.081 & 1.029 & -.112 & -.067 \\
\hline 10. E-mentor must be polite to learners & -.039 & .081 & .744 & .073 & -.176 \\
\hline 08. E-mentor should use words that do not confuse or demotivate learners & .031 & .073 & .629 & .068 & .114 \\
\hline $\begin{array}{l}\text { 04. E-mentor can distinguish between when to consult teachers and when to use his } \\
\text { or her own discretion without consultation }\end{array}$ & .031 & -.016 & .568 & -.005 & .130 \\
\hline 11. E-mentor should not provide feedback to only some intimate learners & .003 & .224 & .469 & .133 & .007 \\
\hline 19. E-mentor can perform the task assigned by teachers accurately & -.102 & .001 & .009 & 1.018 & -.038 \\
\hline 22. E-mentor can work with teachers while consulting & .139 & -.097 & .009 & .774 & .015 \\
\hline 01. E-mentor can offer support to motivate learners & .022 & .073 & -.024 & -.123 & .898 \\
\hline 02. E-mentor can grasp progress of learners' learning & -.047 & .136 & -.072 & .132 & .613 \\
\hline Eigenvalue & 10.05 & 2.05 & 1.39 & 1.17 & 1.07 \\
\hline$\%$ of variance explained & 45.70 & 9.31 & 6.31 & 5.31 & 4.85 \\
\hline
\end{tabular}



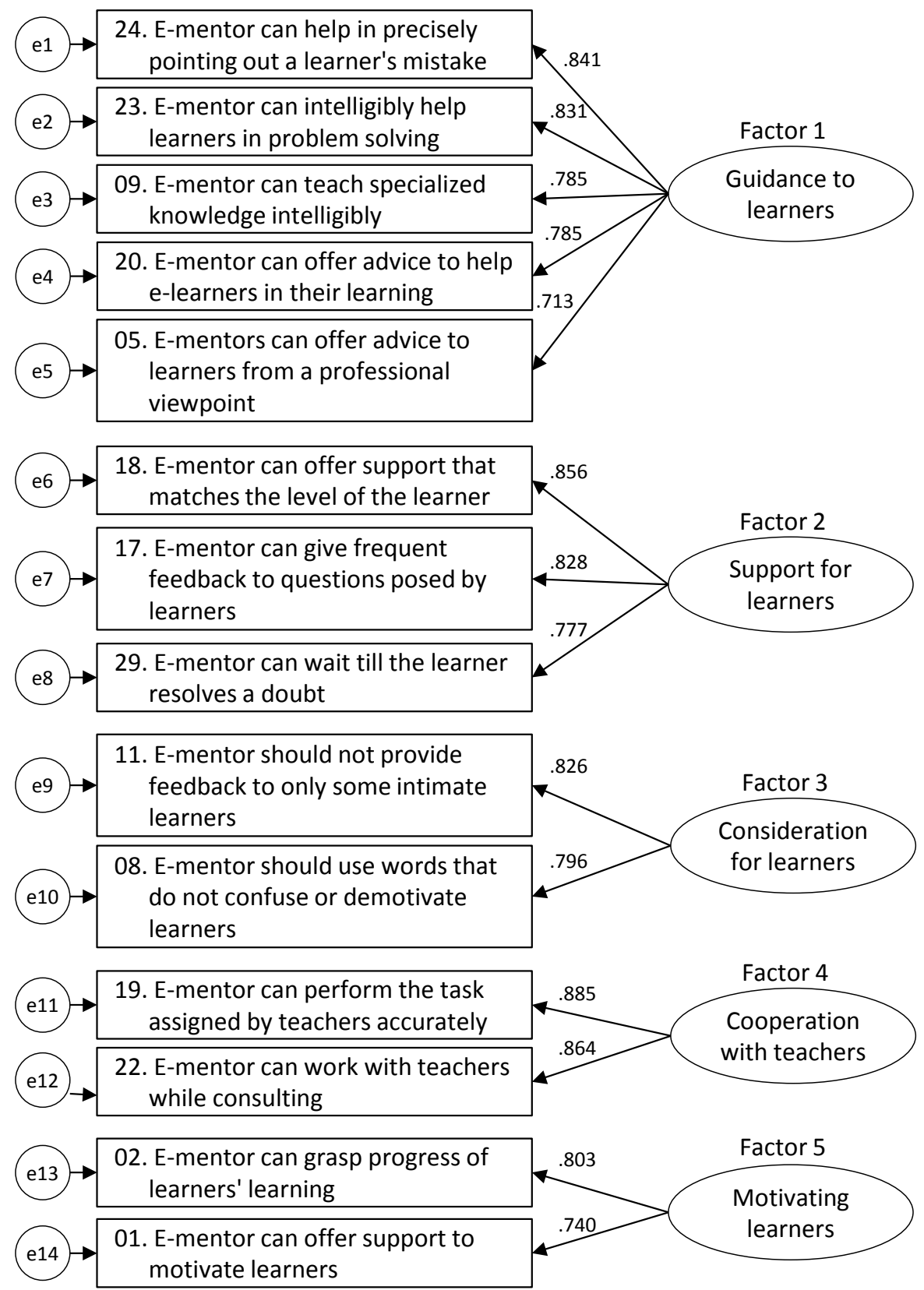

$\mathrm{GFI}=0.915, \mathrm{AGFI}=0.867, \mathrm{CFI}=0.970, \mathrm{RMSEA}=0.061$

Figure 1. Confirmatory factor analysis results

Table 4. Factor correlation

\begin{tabular}{|c|c|c|c|c|c|}
\hline & $\begin{array}{c}\text { F1 } \\
\text { Guidance to } \\
\text { learners } \\
\end{array}$ & $\begin{array}{c}\mathrm{F} 2 \\
\text { Support for } \\
\text { learners }\end{array}$ & $\begin{array}{c}\text { F3 } \\
\text { Consideration for } \\
\text { learners } \\
\end{array}$ & $\begin{array}{c}\mathrm{F} 4 \\
\begin{array}{c}\text { Cooperation with } \\
\text { teachers }\end{array} \\
\end{array}$ & $\begin{array}{c}\text { F5 } \\
\text { Motivating learners }\end{array}$ \\
\hline F1 Guidance to learners & & 0.861 & 0.563 & 0.620 & 0.409 \\
\hline F2 Support for learners & & & 0.776 & 0.662 & 0.553 \\
\hline $\begin{array}{c}\text { F3 Consideration for } \\
\text { learners }\end{array}$ & & & & 0.607 & 0.484 \\
\hline $\begin{array}{l}\text { F4 Cooperation with } \\
\text { teachers }\end{array}$ & & & & & 0.391 \\
\hline F5 Motivating learners & & & & & \\
\hline
\end{tabular}


Table 5. Mean and S.D.

\begin{tabular}{cccccc}
\hline & $\begin{array}{c}\text { F1 } \\
\text { Guidance to learners }\end{array}$ & $\begin{array}{c}\text { F2 } \\
\text { Support for learners }\end{array}$ & $\begin{array}{c}\text { F3 } \\
\text { Consideration for } \\
\text { learners }\end{array}$ & $\begin{array}{c}\text { F4 } \\
\text { Cooperation with } \\
\text { teachers }\end{array}$ & $\begin{array}{c}\text { F5 } \\
\text { Motivating learners }\end{array}$ \\
\hline Mean & 4.33 & 4.08 & 3.86 & 4.07 & 4.28 \\
S.D. & 0.61 & 0.74 & 0.93 & 0.79 & 0.67 \\
\hline
\end{tabular}

\subsection{E-mentor Attributes}

We compared the e-mentor attributes obtained by exploratory factor analysis with Scandura's [13] face-to-face mentoring functions (vocational mentoring, role modeling, and social support). Factor 1, "Guidance to learners" were very similar to "vocational mentoring", and factor 5, "Motivating learners" was very similar to "social support". Both e-mentors and face-to-face mentors offered learners advice from a professional viewpoint and support to motivate them. Thus, "Guidance to learners" and "Motivating learners" had high mean values (see Table 4) as learners emphasized these factors.

Factor 2, "Support for learners" and factor 3, "Consideration for learners" are specific factors of online mentoring. As indicated by Morris and Zuluaga [12], in asynchronous communication, mentors are required to provide prompt and frequent feedback. In addition, nonverbal communication is possible in face-to-face mentoring, whereas it is primarily verbal in online mentoring. A previous study [2], mentioned likelihood of miscommunication, requiring competency in written communication, and technical skills as e-mentoring disadvantages. Therefore, attention to wording was emphasized (e.g., 08. E-mentor should use words that do not confuse or demotivate learners). Item "11. E-mentor should not provide feedback to only some intimate learners" on "Consideration for learners" was also unique to online learning. In online learning, discussions are often conducted in chat rooms or social networking spaces where e-mentors can also participate in the discussion. Hence, e-learners were concerned that it was possible to view the kind of comments e-mentors made to anyone.

The last factor, "Cooperation with teachers", may be conceived as unique to Japanese e-mentors. As described in the Introduction, few Japanese universities have an adequate e-mentor system [19]. In addition, in one case despite establishing an e-mentor system, it was not utilized even once [20]. Even if e-mentors are experts with master's degrees like X University's e-mentors, e-learners' reliability may be low. Therefore, e-learners want e-mentors to work with teachers while mentoring.

The above results support both Hypothesis 1 and Hypothesis 2. "Guidance to learners" and "Motivating learners" are attributes required for both face-to-face mentoring and e-mentoring, but "Support for learners" and "Consideration for learners" are attributes that compensate for online shortcomings. In addition, "Cooperation with teachers" was a factor reflecting
Japanese e-learning circumstances.

\section{Conclusions}

This study identified five factors that enhanced the attributes of e-mentors by conducting an original questionnaire survey. Factor names were determined as below. Factor 1 was named "Guidance to learners," comprising five items, Factor 2, "Support for learners," comprising three items, Factor 3, "Consideration for learners," comprising two items, Factor 4, "Cooperation with teachers," comprising two items, Factor 5, "Motivating learners," comprising two items. Among these, "Guidance to learners" and "Motivating learners" are common factors with face-to-face mentoring. "Support for learners" and "Consideration for learners" are unique e-mentoring factors. "Cooperation with teachers" is a factor unique to e-mentoring in Japan.

\section{Note}

A part of this study was presented as a verbal announcement at the 3rd International Conference on Education and Psychology.

\section{Acknowledgements}

This work was supported by JSPS KAKENHI Grant Number JP26350336.

\section{REFERENCES}

[1] E. A. Ensher, S. E. Murphy. E-mentoring: Next-generation research strategies and suggestions. In B. R. Ragins, K. E. Kram (Eds.), The handbook of mentoring at work: Theory, research, and practice (pp. 299-322). Sage, Thousand Oaks, CA, 2007.

[2] E. A. Ensher, C. Heun, A. Blanchard. Online mentoring and computer-mediated communication: New directions in research, Journal of Vocational Behavior, Vol. 63, 264-288, 2003.

[3] S. Knouse. Virtual mentors: Mentoring on the Internet, Journal of Employment Counseling, Vol. 38, 162-168, 2001. 
[4] P. B. Single, R. M. Single. E-mentoring for social equity: review of research to inform program development, Mentoring \& Tutoring, Vol. 13, No. 2, 301-320, 2005.

[5] K. Tamaki, M. Kosakai, T. Matsuda. E-learning jissenhou: Cyber alliance no sekai (Practice method of e-Learning: The world of cyber alliance), Ohmsha, Tokyo, 2003.

[6] T. Matsuda, M. Harada. E-learning no tameno mentoring: Gakushushashien no jissen (Mentoring for e-learning: Practice of learner support), Tokyo Denki University, Tokyo, 2007.

[7] M. Allen. Michael Allen's Guide to E-learning: Building Interactive, Fun, and Effective Learning Programs for any Company, John Wiley \& Sons, Hoboken, New Jersey, 2002 .

[8] S. C. de Janasz, E. A. Ensher, C. Heun. Virtual relationships and real benefits: using e-mentoring to connect business students with practicing managers, Mentoring \& Tutoring: Partnership in Learning, Vol.16, No.4, 394-411, 2008.

[9] S. C. de Janasz, V. M. Godshalk. The role of e-mentoring in protégés' learning and satisfaction, Group \& Organization Management, Vol. 38, No. 6, 743-774, 2013.

[10] K. Burner. From candidate to colleague: Mentoring online doctoral students, The Journal of Online Doctoral Education, Vol. 1, 101-111, 2014.

[11] L. Rademaker. Chair perceptions of trust between mentor and mentee in online doctoral dissertation mentoring, online Learning, Vol. 20, No. 1, 2016.

[12] E. J. S. Morris, C. P. Zuluaga. Educational effectiveness of $100 \%$ online IT courses, Interact, Integrate, Impact: Proceedings 20th ASCILITE Conference, Adelaide, 353-363, 2003.

[13] T. A. Scandura. Mentorship and career mobility: An empirical investigation, Journal of Organizational Behavior, Vol. 13, No. 2, 169-174, 1992.

[14] K. E. Kram. Mentoring at Work, Scott Foresman, Glenview, IL. 1985.

[15] R. J. Burke. Mentors in organizations, Group and Organization Studies, 9, 353-372, 1984.

[16] A. Yoshida. Chapter 12 World expansion of e-learning in higher education, Human information science and e-learning, Foundation for the promotion of the open university of Japan, Tokyo, 2006.

[17] K. Seki, A. Tominaga, C. Kogo. A study on retrospection and prospect of adult learners who graduated from an online University, Japan Journal of Educational Technology, Vol. 38, No. 2, 101-112, 2014.

[18] N. Ishikawa, C. Kogo. Self-regulated learning and problem-solving strategies used by students in online universities, Japan Journal of Educational Technology, Vol. 41, No. 4, 329-343, 2018.

[19] A. Yoshida, M. Taguchi. Mosakusareru e-learning jirei to chousa data nimiru daigaku no mirai (The e-learning case studied and the future of the university in survey data), Toshindou, Tokyo, 2005.

[20] M. Fukumoto, S. Sakaguchi. Issues of public vocational training utilizing e-learning: from the consciousness of IT literacy education training participants, Research on Industrial Education, Vol. 33, No. 2, 49-56, 2003.

[21] J. Kawakita. Hassouhou: Souzousei kaihatsu no tameni (The abduction method: for creativity development), Chuou Kouron-Sha, Tokyo, 1967.

[22] S. Raymond. The KJ method: A technique for analyzing data derived from Japanese ethnology, Human Organization, Vol. 56, No. 2, 233-237, 1997. 